\title{
Effects of inclusion size and stress ratio on fatigue strength for high-strength steels with fish-eye mode failure
}

\author{
Chengqi Sun, Zhengqiang Lei, Jijia Xie, Youshi Hong* \\ State Key Laboratory of Nonlinear Mechanics, Institute of Mechanics, Chinese Academy of Sciences, Beijing 100190, China
}

\section{A R T I C L E I N F O}

Article history:

Received 19 September 2012

Received in revised form 27 November 2012

Accepted 1 December 2012

Available online 12 December 2012

\section{Keywords:}

Very-high-cycle fatigue

Inclusion size

Stress ratio

Fatigue strength

High-strength steels

\begin{abstract}
A B S T R A C T
Experimental results indicate that the fatigue life reduces by about two orders of magnitude when inclusion size doubles. Then, a model is proposed for predicting the fatigue strength of high-strength steels with fish-eye mode failure based on the experimental results for the effect of inclusion size and stress ratio. In the model, the effect of inclusion size $a_{0}$ and stress ratio $R$ on fatigue strength $\sigma_{a}$ is expressed as $\sigma_{a} \propto a_{0}{ }^{m}[(1-R) / 2]^{\alpha}$, where $m$ and $\alpha$ are material parameters. The predicted results are in good agreement with our experimental results and the ones reported in literature.
\end{abstract}

(c) 2012 Elsevier Ltd. All rights reserved.

\section{Introduction}

Since the work by Naito et al. [1], a number of researches have shown that fatigue failures of high-strength steels may occur at the stress lower than the conventional fatigue limit defined at failure cycles of $10^{7}[2-7]$. Different from low cycle fatigue, the crack initiation site for the fatigue life larger than $10^{7}$ (very-high-cycle fatigue, VHCF) for high-strength steels usually changes from the surface to the interior of specimen and the failure is mostly caused by interior non-metallic inclusions. Further, a fish-eye fracture mode often presented with the morphology of fine granular area (FGA) [8], also called optical dark area (ODA) [9] or granularbright-facet (GBF) [10] observed around the inclusion at fracture origin. The term of FGA is used in this paper.

Many researches have shown that inclusion size has great influence on VHCF properties of high strength steels [11]. The studies by Murakami et al. [12] indicated that the relative size of FGA to that of the inclusion at the fracture origin increased with the increase of the fatigue life and that the formation of FGA played a crucial role in VHCF failure. Zhao et al. [13] investigated the formation mechanism of FGA in high-strength steels and proposed a model to predict the threshold value of its formation based on the plastic zone at crack tip. It was shown that the stress intensity factor range at the front of FGA kept constant and was close to the threshold value of the crack propagation $\Delta K_{\mathrm{th}}$. The similar results were reported by Shiozawa et al. [10,14] and Sakai [15], which

\footnotetext{
* Corresponding author. Tel.: +86 10 82543966; fax: +86 1062561284

E-mail address: hongys@imech.ac.cn (Y. Hong).
}

showed that the stress intensity factor range at the front of FGA kept constant value corresponding to the threshold value of the crack propagation for a kind of high carbon chromium steel.

Some methods are also proposed to predict the fatigue life or fatigue strength containing VHCF regime [16-19]. Murakami et al. $[9,20]$ combined the parameters of fatigue strength $\sigma$ (MPa), Vickers hardness $\mathrm{Hv}\left(\mathrm{kgf} / \mathrm{mm}^{2}\right)$ and the square root of inclusion or defect projection area $\sqrt{\text { area }}(\mu \mathrm{m})$ to give an equation for predicting the fatigue strength of high-strength steels:

$\sigma=\frac{C(\mathrm{Hv}+120)}{(\sqrt{\text { area }})^{1 / 6}}\left(\frac{1-R}{2}\right)^{\alpha}$

where $R$ is the stress ratio, $\alpha=0.226+\mathrm{Hv} \times 10^{-4}, C=1.43$ for surface inclusions or defects and $C=1.56$ for interior inclusions or defects.

Wang et al. [21] incorporated the number of cycles to failure into Murakami's model and proposed:

$\sigma=\frac{\beta(\mathrm{Hv}+120)}{(\sqrt{\text { area }})^{1 / 6}}\left(\frac{1-R}{2}\right)^{\alpha}$

where $\beta=3.09-0.12 \log N_{f}$ for interior inclusions or defects and $\beta=2.79-0.108 \log N_{f}$ for surface inclusions or defects for four lowalloy high-strength steels (42Cr-Mo4, Cr-Si (54SC6), Cr-Si (55SC7) and $\mathrm{Cr}-\mathrm{V}(60 \mathrm{CV} 2)$ ).

Akiniwa et al. [22] assumed that Paris relation was still valid for the fatigue crack propagation in FGA, and derived an approximate relation for the fatigue strength and the number of cycles to failure: 
$\left(\Delta K_{\text {Inc }}\right)^{m_{\mathrm{A}}}\left(\frac{N_{f}}{\sqrt{\text { area }_{\text {Inc }}}}\right)=\frac{2}{C_{\mathrm{A}}\left(m_{\mathrm{A}}-2\right)}$

where the subscript "Inc" denotes inclusion. Tanaka and Akiniwa [23] gave the parameters $m_{\mathrm{A}}=14.2$ and $C_{\mathrm{A}}=3.44 \times 10^{-21}$ for bearing steel JIS SUJ2 with the tensile strength of $2316 \mathrm{MPa}$. Then, the model by Akiniwa et al. [22] was modified as

$\sigma_{a}=\frac{2}{\sqrt{\pi}}\left(\frac{2}{C_{\mathrm{A}}\left(m_{\mathrm{A}}-2\right)}\right)^{\frac{1}{m_{\mathrm{A}}}}\left(\sqrt{\text { area }_{\text {Inc }}}\right)^{\frac{1}{m_{\mathrm{A}}}}-\frac{1}{2} N_{f}^{-\frac{1}{m_{\mathrm{A}}}}$

Chapetti et al. [24] showed a relation between FGA size, inclusion size and the number of cycles to failure in the form of $\sqrt{\operatorname{area}_{\mathrm{FGA}}} / \sqrt{\operatorname{area}_{\text {Inc }}}=0.25 N_{f}^{0.125}$ by fitting the experimental data of quenched and tempered JIS SUJ2, SCM435 and SNCM439 steels, and then proposed an expression to correlate the total fatigue life with the threshold stress $\sigma_{\text {th }}$ as

$\Delta \sigma_{\mathrm{th}} N_{f}^{\frac{1}{48}}=4.473 \frac{\mathrm{Hv}+120}{R_{i}^{1 / 6}}$

where $\Delta \sigma_{\text {th }}$ in MPa, $R_{i}=\sqrt{\mathrm{area}_{\mathrm{Inc}} / \pi}$ in $\mu \mathrm{m}$, and $\mathrm{Hv}$ in $\mathrm{kgf} / \mathrm{mm}^{2}$.

Here, we omit the subscript "th" and note $\Delta \sigma_{\mathrm{th}}=2 \sigma_{a}$, Eq. (5) is rewritten as

$\sigma_{a}=2.460 \frac{\mathrm{Hv}+120}{\left(\sqrt{\text { area }_{\text {Inc }}}\right)^{1 / 6}} N_{f}^{\frac{1}{48}}$

Mayer et al. [25] pointed out that the fatigue life is approximated by the stress amplitude and the inclusion size by the formula

$$
\left[\sigma_{a}\left(\sqrt{\text { area }_{\text {Inc }}}\right)^{1 / 6}\right]^{n} N_{f}=C
$$

where $n=28.82$ and $C=6.47 \times 10^{98}$ by fitting the fatigue data of specimens failed from interior inclusions for bainitic bearing $100 \mathrm{Cr} 6$ steel with tensile strength of $2387 \mathrm{MPa}$, and the dimension of stress amplitude is MPa and area Inc $_{\text {in }} \mu \mathrm{m}^{2}$.

This relation is rearranged as

$\sigma_{a}=C^{\frac{1}{n}} \frac{1}{\left(\sqrt{\left.\text { area }_{\text {Inc }}\right)^{1 / 6}}\right.} N_{f}^{-\frac{1}{n}}$

Liu et al. [26] proposed an expression in form of Basquin equation for predicting the $S-N$ curves based on the prediction of fatigue strengths at $10^{6}$ cycles and at $10^{9}$ cycles, i.e.

$\sigma_{a}=\sigma_{f}^{\prime}\left(2 N_{f}\right)^{b}$

where $\quad \sigma_{f}^{\prime}=1.12(\mathrm{Hv}+120)^{9 / 8} /\left(\sqrt{\text { area }_{\text {Inc }}}\right)^{1 / 8} \quad$ and $b=3^{-1} \log _{10}\left[1.35(\mathrm{Hv}+120)^{-1 / 16}\left(\sqrt{\text { area }_{\text {Inc }}}\right)^{-1 / 48}\right]$, with $\sigma_{a}$ in MPa, $\sqrt{\operatorname{area}_{\text {Inc }}}$ in $\mu \mathrm{m}$ and $\mathrm{Hv}$ in $\mathrm{kgf} / \mathrm{mm}^{2}$.

It can be expressed as

$\sigma_{a}=1.12 \frac{2^{b}(\mathrm{Hv}+120)^{9 / 8}}{\left(\sqrt{\text { area }_{\text {Inc }}}\right)^{1 / 8}} N_{f}^{b}$

Recently, Sun et al. [27] developed a model for estimating the fatigue life of high-strength steels in high cycle and VHCF regimes with fish-eye mode failure based on the cumulative fatigue damage, which takes into account the inclusion size $\sqrt{\operatorname{area}_{\text {Inc }}}$, FGA size $\sqrt{\operatorname{area}_{\mathrm{FGA}}}$ and tensile strength $\sigma_{b}$ of materials

$N_{f}=10^{\alpha \frac{\sigma_{b}}{\sigma_{a}}} \ln \frac{\operatorname{area}_{\mathrm{FGA}}}{\operatorname{area}_{\mathrm{Inc}}}$

or

$N_{f}=2 \times 10^{\alpha_{\frac{b}{\sigma a}}} \ln \frac{\sqrt{\operatorname{area}_{\mathrm{FGA}}}}{\sqrt{\operatorname{area}_{\mathrm{Inc}}}}$

where $\alpha$ is the parameter by fitting the experimental data.

It is seen that, for several models (Eqs. (1), (2), (6), and (8)) mentioned above, the effect of inclusion size on fatigue strength (i.e. the power exponent of $\sqrt{\operatorname{area} \text { Inc }}$ ) is regarded as a constant, while for the other models (Eqs. (4), (10), and (12)), the effect of inclusion size on fatigue strength is related to the material. Thus, the model to describe the effect of inclusion size on fatigue strength still needs to be further developed.

In this paper, ultrasonic $(20 \mathrm{kHz})$ fatigue tests are performed on specimens of a high carbon chromium steel in order to further investigate the effect of inclusion size on the fatigue life. Then, a model is developed for the effect of inclusion size and stress ratio on fatigue strength of high-strength steels with fish-eye mode failure. The predicted results are in good agreement with our experimental data and the ones reported in literature. The model is also compared with some previous ones, with the comparison showing the superior of the present one.

\section{Experimental procedure}

The material used in the present paper is a high carbon chromium steel, with the main chemical compositions of $1.06 \mathrm{C}$, $1.04 \mathrm{Cr}, 0.88 \mathrm{Mn}, 0.34 \mathrm{Si}, 0.027 \mathrm{P}$ and $0.005 \mathrm{~S}$ in mass percentage ( $\mathrm{Fe}$ balance). Specimens were heated at $845^{\circ} \mathrm{C}$ for $2 \mathrm{~h}$ in vacuum, then oil-quenched and tempered for $2.5 \mathrm{~h}$ at $150{ }^{\circ} \mathrm{C}$ in vacuum with furnace-cooling. The hardness measurement was performed on two specimens by a Vickers hardness tester at a load of $50 \mathrm{~g}$ with the load holding time of $15 \mathrm{~s}$. Fifteen points were tested on each specimen and the average Vickers hardness was $808 \mathrm{kgf} / \mathrm{mm}^{2}$. The tensile test was conducted on three cylindrical specimens with diameter $6 \mathrm{~mm}$ by an MTS 810 machine, and the average tensile strength was $2163 \mathrm{MPa}$. The round notch surface was ground and final polished to eliminate machine scratches before fatigue testing. The geometry of specimen is shown in Fig. 1.

The fatigue tests were conducted on a Shimadzu USF-2000 at a resonance frequency of $20 \mathrm{kHz}$ at room temperature in air with a resonance interval of $100 \mathrm{~ms}$ per $500 \mathrm{~ms}$ (i.e. the machine stops for $100 \mathrm{~ms}$ when it operates for $500 \mathrm{~ms}$ ). Compressive cold air was used to cool the specimens during ultrasonic fatigue testing. The stress ratio $R$ is -1 , and two stress levels ( $\sigma_{a}=860 \mathrm{MPa}$ and $\sigma_{a}=880 \mathrm{MPa}$ ) are chosen for the fatigue tests. The fracture surfaces of failed specimens were observed by a field-emission type scanning electron microscope (SEM), and the inclusion size and FGA size of crack origin were measured from the SEM photos by using Image-Pro Plus (IPP) software. The aim of the fatigue tests in this paper is to investigate the effect of inclusion size on the scatter of fatigue life from high cycle to VHCF regimes under the same stress level. In order to obtain more experimental data failed from interior inclusions of specimen, this paper arranges two stress levels with small difference of $20 \mathrm{MPa}$ in the tests.

\section{Experimental results and analysis}

\subsection{Experimental results}

It is observed that the fish-eye mode fracture of tested specimens is originated from a single crack origin, i.e. an inclusion. The fatigue test data and the related inclusion size $a_{0}$ and FGA size

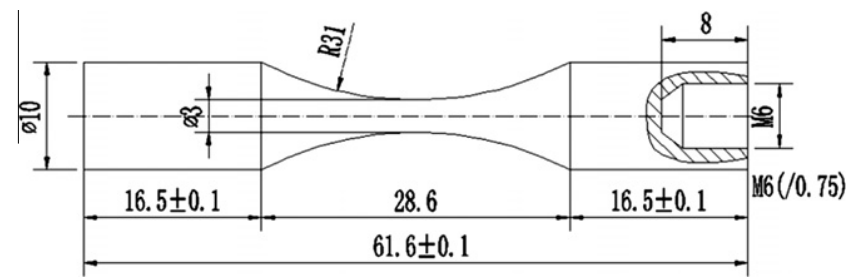

Fig. 1. Specimen geometry, dimensions in $\mathrm{mm}$. 
Table 1

Data of fatigue test and fracture origins.

\begin{tabular}{cllll}
\hline Specimen code & $\sigma_{a}(\mathrm{MPa})$ & $N_{f}$ & $a_{0}(\mu \mathrm{m})$ & $a_{\mathrm{FGA}}(\mu \mathrm{m})$ \\
\hline 1 & 860 & $4.53 \times 10^{5}$ & 41.1 & 43.3 \\
2 & 860 & $6.06 \times 10^{5}$ & 59.5 & 63.2 \\
3 & 860 & $7.15 \times 10^{5}$ & 40.1 & 45.4 \\
4 & 860 & $2.81 \times 10^{6}$ & 37.5 & 44.5 \\
5 & 860 & $7.20 \times 10^{6}$ & 36.7 & 43.7 \\
6 & 860 & $7.33 \times 10^{6}$ & 32.5 & 54.4 \\
7 & 860 & $1.43 \times 10^{8}$ & 19.5 & 37.5 \\
8 & 880 & $7.05 \times 10^{5}$ & 52.1 & 54.1 \\
9 & 880 & $1.67 \times 10^{6}$ & 48.9 & 55.8 \\
10 & 880 & $1.02 \times 10^{7}$ & 29.2 & 50.4 \\
11 & 880 & $1.09 \times 10^{7}$ & 29.5 & 37.6 \\
12 & 880 & $5.54 \times 10^{7}$ & 19.9 & 39.6 \\
13 & 880 & $1.29 \times 10^{8}$ & 30.8 & 52.8 \\
\hline
\end{tabular}

$a_{\mathrm{FGA}}$ observed for the specimens induced by interior inclusions are listed in Table 1 , in which $a_{0}$ is the positive square root of inclusion projection area and $a_{\mathrm{FGA}}$ is positive square root of FGA area including the inclusion projection area as used by Murakami et al. [12]. It is noted that two specimens failed from surface inclusion for $\sigma_{a}=860 \mathrm{MPa}$, and the fatigue lives are $7.11 \times 10^{4}$ and $3.19 \times 10^{5}$, respectively. For $\sigma_{a}=880 \mathrm{MPa}$, one specimen failed from surface inclusion with the fatigue life of $1.28 \times 10^{5}$. The other specimens failed from the interior inclusion with a fish-eye pattern (Fig. 2).

Fig. 3 shows the $S-N$ data. It is seen that the scatter of the fatigue life for interior inclusion initiation is very large which exceeds more than two orders of magnitude (from less than $10^{6}-10^{8}$ ) under the same stress level. It is noted that the shape of $S-N$ curve for high-strength steels often presents a duplex pattern corresponding to surface-initiated fracture mode and interior-initiated fracture mode $[8,10,15,28]$. So, the stress levels in the present test correspond to the stress level of plateau region.

\subsection{Effect of inclusion size on fatigue life}

Fig. 4 plots the fatigue life versus inclusion size under the same stress level, i.e. $\sigma_{a}=860 \mathrm{MPa}$ and $\sigma_{a}=880 \mathrm{MPa}$, respectively. It is seen that the fatigue life is almost linearly related to the inclusion size implying that the inclusion size plays an important role in VHCF properties of high-strength steels. Fig. 4 also indicates that, for the same stress level, the fatigue life and the inclusion size are well correlated by a linear relation with logarithmic scales. A fitting line (correlation coefficient being -0.86 ) is shown for the fatigue life and the inclusion size in Fig. 4, in which the two stress levels are not differentiated by the consideration that the two

(a)

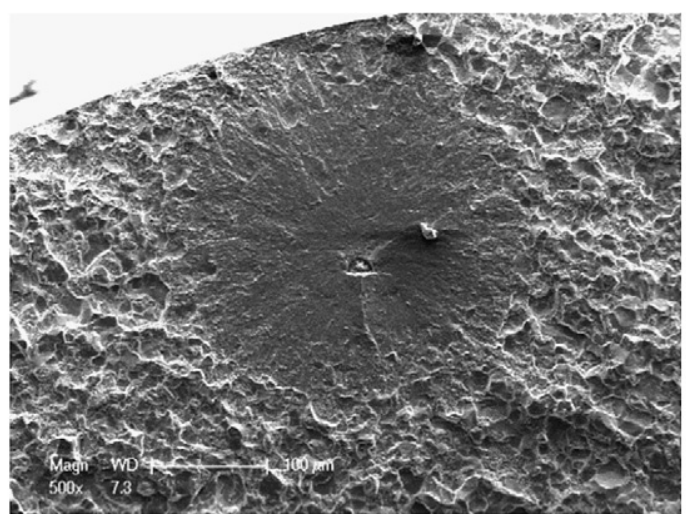

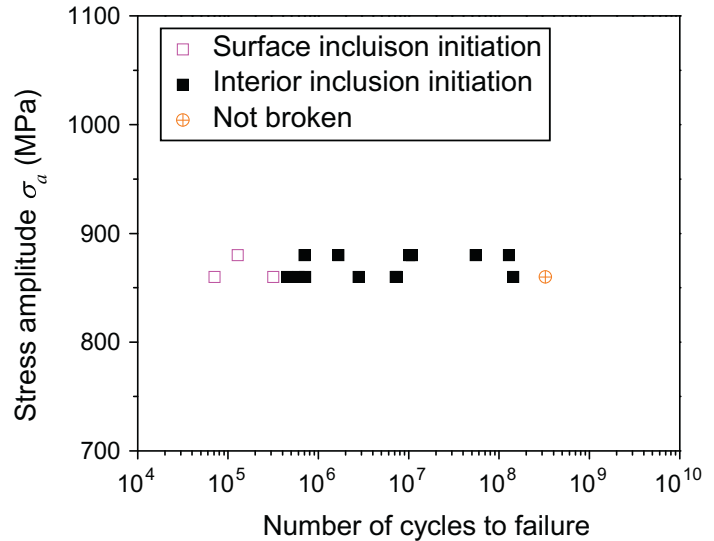

Fig. 3. $S-N$ diagram.

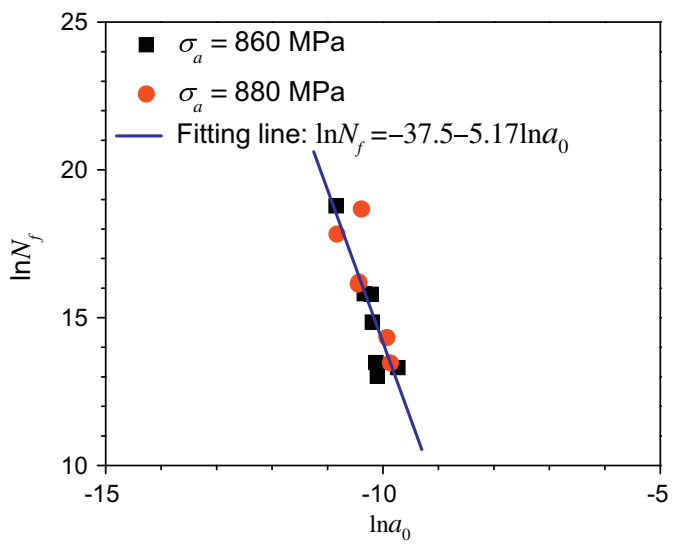

Fig. 4. Fatigue life versus inclusion size under the same stress level.

stress levels have small difference of $20 \mathrm{MPa}$ in the test. From the fitting result, the fatigue life reduces to $2.8 \%$ when inclusion size doubles, i.e. the fatigue life reduces by about two orders of magnitude when inclusion size doubles.

\section{Fatigue strength model and analysis}

Based on the results that the fatigue life is correlated to inclusion size under the same stress level, we may write

(b)

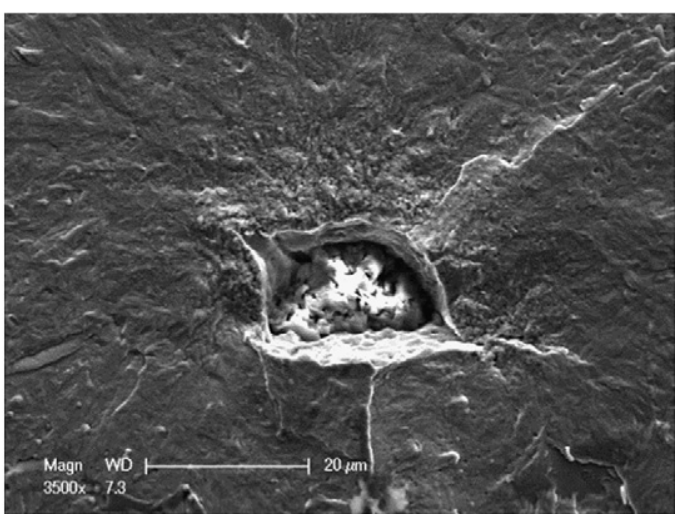

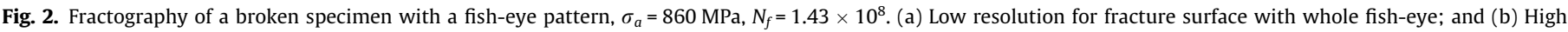
resolution for FGA in crack origin. 
$N_{f}=A a_{0}^{q}$

As known, the stress amplitude is one of the uppermost factors influencing fatigue life. Thus, the parameter $A$ should be at least a function related to the stress amplitude, i.e. $N_{f} a_{0}^{-q}=f\left(\sigma_{a}\right)$. The shape of $S-N$ curve for high-strength steels often presents a duplex pattern corresponding to surface-initiated fracture mode and interior-initiated fracture mode $[8,10,15,28]$. So, if the inclusion size $a_{0}$ varies in a very small range (i.e. $a_{0}$ is regard as a constant), Eq. (13) should reflect the traditional form of $S-N$ curve (i.e. $N_{f}=C^{\prime} \sigma_{a}^{b}$ ). Therefore, it is thought that the function $f\left(\sigma_{a}\right)$ is a power function of $\sigma_{a}$. For validating this supposition, Fig. 5 illustrates the experimental values of $\ln \left(N_{f} a_{0}^{5.17}\right)$ as a function of $\ln \sigma_{a}$ with the fitting result of the present experimental data and our previous ones of $\mathrm{GCr} 15\left(\mathrm{Hv}=820 \mathrm{kgf} / \mathrm{mm}^{2}\right)$ with the same heat treatment. It is observed that the values of $\ln \left(N_{f} a_{0}^{5.17}\right)$ and those of $\ln \sigma_{a}$ are well approximated by a linear relation in logarithmic scales. The correlation coefficient is -0.61 , which is mainly due to the less difference in $\sigma_{a}$. This indicates that $N_{f} a_{0}^{5.17}$ can be approximated by a power function of $\sigma_{a}$, i.e. the fatigue strength, fatigue life and inclusion size can be correlated by the form of

$\sigma_{a}=C_{f}^{l} a_{0}^{m}$

with $C=e^{19.2}, l=-0.0371$ and $m=-0.192$.

Fig. 6 shows the comparison of the fatigue strength obtained by Eq. (14) using different inclusion sizes with experimental results shown in Fig. 5. It is seen that Eq. (14) reflects the effect of inclusion size on the fatigue strength. Fig. 6 also indicates the fact that the inclusion size has great influence on fatigue strength of high-strength steels [11].

In the following, the form by Eq. (14) is used to predict the fatigue strength of high-strength steels with fish-eye mode failure, and $m$ is usually taken as -0.192 for relevant high-strength steels.

Fig. 7 shows the comparison of fatigue strength obtained by Eq. (14) using different inclusion sizes with the corresponding experimental data obtained from our previous experiments and reported in literature, in which the parameters $C$ and $l$ are determined by fitting the experimental data. It is seen that the fatigue strength obtained by Eq. (14) using the minimum inclusion size is generally higher than the experimental results, while the fatigue strength using the maximum inclusion size is generally smaller than the experimental ones. The fatigue strength obtained by Eq. (14) using average inclusion size is moderate to the experimental results, and the corresponding $S-N$ curve obtained seems to be the median $S-N$ curve. This indicates that Eq. (14) is able to

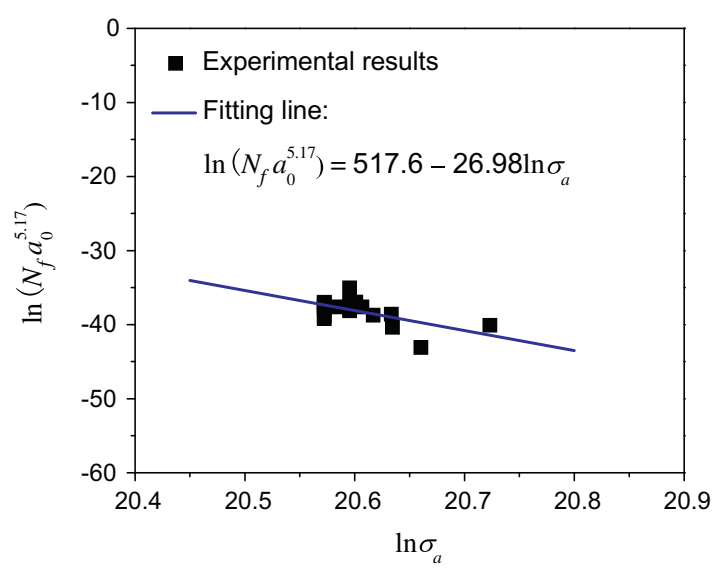

Fig. 5. Experimental values of $\ln \left(N_{f} a_{0}^{5.17}\right)$ as a function of $\ln \sigma_{a}$ with fitting result for present experimental data and our previous ones of GCr15 $\left(\mathrm{Hv}=820 \mathrm{kgf} / \mathrm{mm}^{2}\right)$ [13] with the same heat treatment.

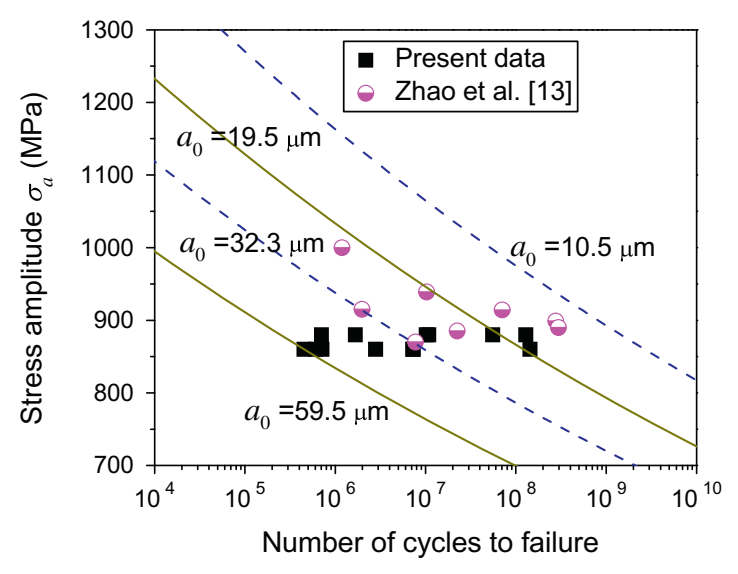

Fig. 6. Comparison of fatigue strength obtained by Eq. (14) with experimental results shown in Fig. 5, in which the solid line denotes the maximum inclusion size and the minimum inclusion size for the present experimental data and the dash line denotes the maximum inclusion size and the minimum inclusion size for our previous experimental data of $\mathrm{GCr} 15\left(\mathrm{Hv}=820 \mathrm{kgf} / \mathrm{mm}^{2}\right)$ [13] with the same heat treatment.

correlate the effect of inclusion size on fatigue strength, and the fatigue strength obtained by Eq. (14) using the maximum inclusion size can be regarded as the lower bound of fatigue strength obtained by experiments. Fig. 7 also shows the comparison of Eq. (14) with our previous model [27] and the model by Liu et al. [26]. It is seen that Eq. (14) is better than such two models for correlating the effect of inclusion size on fatigue strength.

It is noted that in Figs. 6 and 7, we only consider the interior-initiated fracture mode with an FGA surrounding the inclusion at the fracture origin. It is also noted that the parameter $m$ in the present model is related to the material and that there are differences both in the fatigue life and the fish-eye crack growth mechanisms and in resulting shapes and sizes under different loading conditions $[29,32]$. Therefore, the parameter $m$ may not be -0.192 for some high-strength steels and it may also be different for the same material under different loading conditions.

Fig. 8 shows the further comparison of fatigue strength obtained by Eq. (14) with experimental data. Our previous experiment results of a similar steel (GCr15) with similar quenched and tempered procedure under rotary bending test [35] are also presented in Fig. 8a, in which the parameters $C$ and $l$ are fitted by the experimental data by Shiozawa et al. [10] as shown in Fig. 7a. For Fig. 8b, the parameters $C$ and $l$ are fitted by the experimental data with subsurface FGA surrounding the inclusion by Shiozawa et al. [33]. Consider that the inclusion size at crack initiation site under rotary bending fatigue test is between $5.3 \mu \mathrm{m}$ and $21.5 \mu \mathrm{m}$ by Nakajima et al. [32], between $6 \mu \mathrm{m}$ and $12 \mu \mathrm{m}$ by Shiozawa et al. [10], and between $9.4 \mu \mathrm{m}$ and $22.6 \mu \mathrm{m}$ by Hong et al. [35]. The minimum inclusion size $a_{0, \min }=5.3 \mu \mathrm{m}$ and the maximum inclusion size $a_{0, \max }=22.6 \mu \mathrm{m}$ are taken for rotary bending fatigue test in Fig. $8 \mathrm{a}$. The inclusion size at crack initiation site under axial loading fatigue test at $R=-1$ is between $5.9 \mu \mathrm{m}$ and $18.2 \mu \mathrm{m}$ by Nakajima et al. [32], between $11 \mu \mathrm{m}$ and $36 \mu \mathrm{m}$ by Shiozawa et al. [33]. The minimum inclusion size $a_{0, \min }=5.9 \mu \mathrm{m}$ and the maximum inclusion size $a_{0, \max }=36 \mu \mathrm{m}$ are taken for axial loading fatigue test at $R=-1$ in Fig. $8 \mathrm{~b}$. It is seen that the fatigue strength obtained by Eq. (14) using the maximum inclusion size and the minimum inclusion size can be regarded as the lower bound and the upper bound of fatigue strength, respectively, even for the samples without FGA around the inclusion at the fracture origin in Fig. 8b. This further indicates that Eq. (14) can correlate well the effect of inclusion size on fatigue strength, and that 

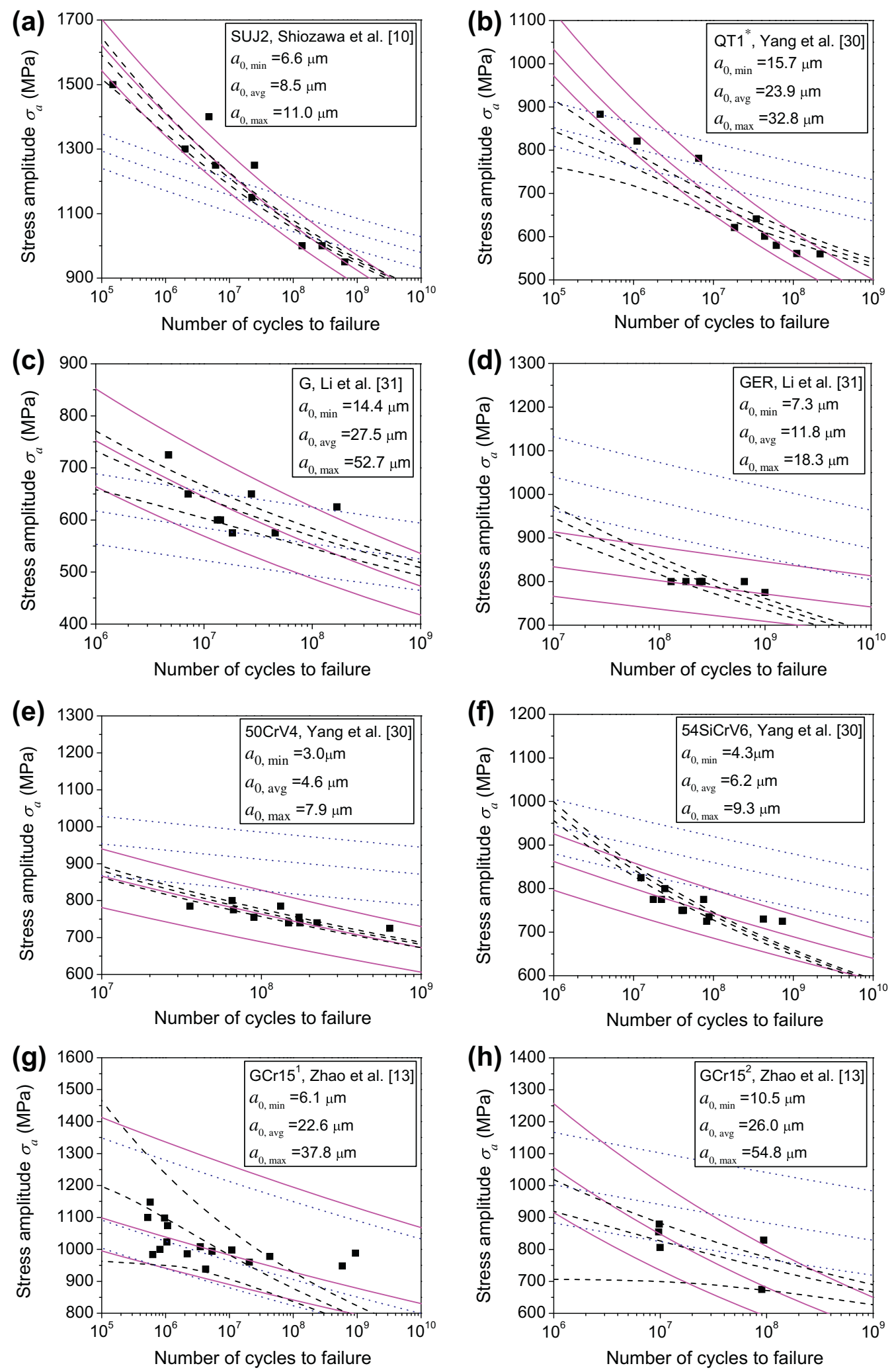

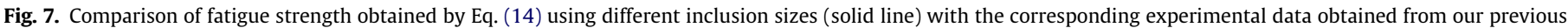

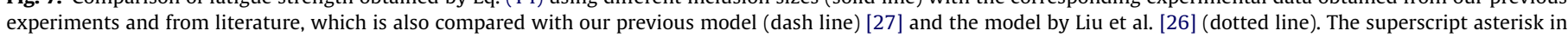

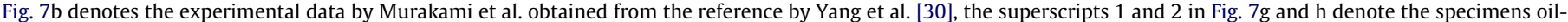

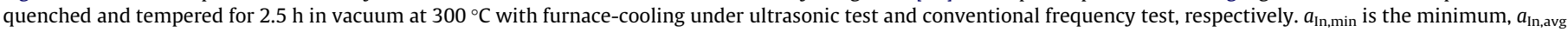
is the average, $a_{\mathrm{In} \text {,max }}$ is the maximum of the inclusion sizes at fracture origin. (See above-mentioned references for further information.)

Eq. (14) with the maximum inclusion size can be used to predict the fatigue strength of high-strength steels with fish-eye mode failure, which may also be of help in the design of the mechanical components concerning VHCF issue. 

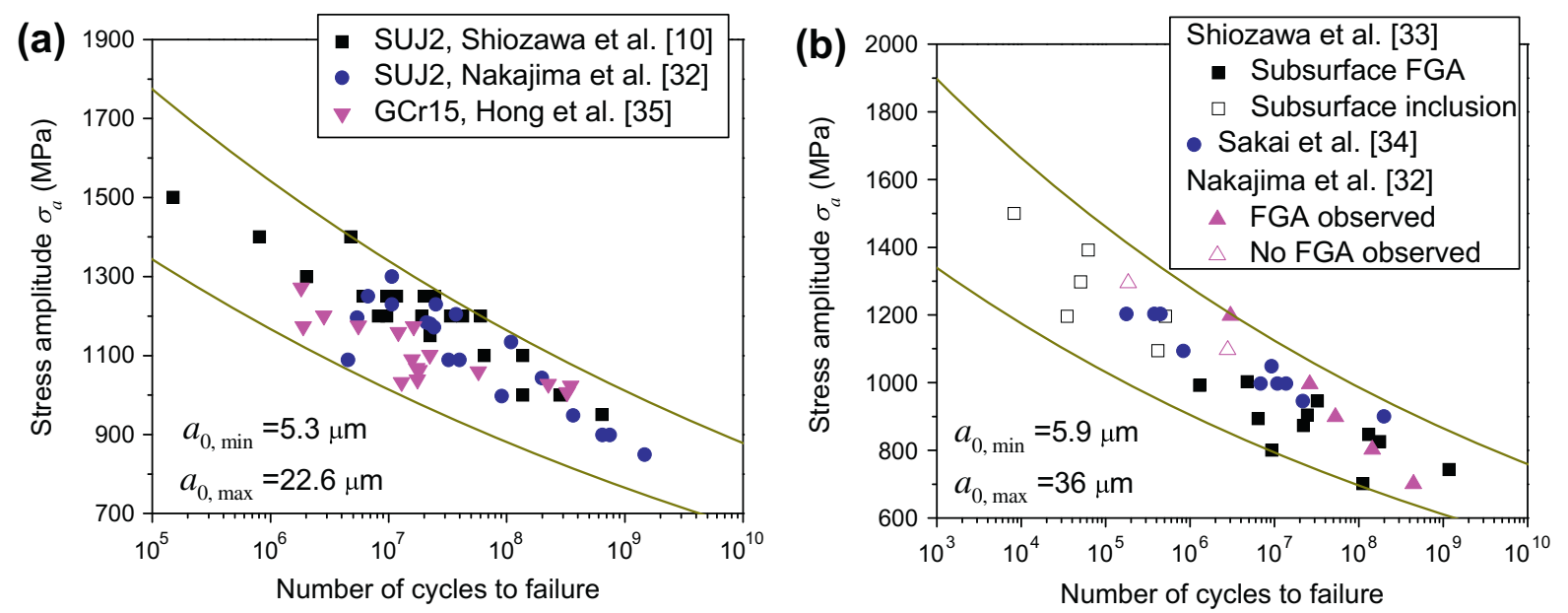

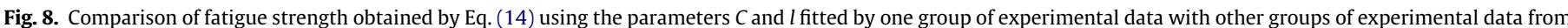
literature. (a) Rotary bending fatigue test, $R=-1$; and (b) Axial loading fatigue test, $R=-1$. (See above-mentioned references for further information.)

\section{Effect of stress ratio on fatigue strength}

In a previous paper [36], the effect of stress ratio on fatigue strength under the same fatigue life is expressed as

$\sigma_{a}=\sigma_{-1}\left(\frac{1-R}{2}\right)^{\alpha}$

where $\sigma_{-1}$ denotes stress amplitude at $R=-1$ and $\alpha$ is a parameter.

Thus, the fatigue strength (Eq. (14)) involving the effect of stress ratio is expressed as

$\sigma_{a}=C N_{f}^{l} a_{0}^{m}\left(\frac{1-R}{2}\right)^{\alpha}$

It is seen that, any of the models by Murakami et al. $[9,20]$ (Eq. (1)), Akiniwa et al. [22] (Eq. (4)), Chapetti et al. [24] (Eq. (6)), or Mayer et al. [25] (Eq. (8)) is a special case of the present model as Eq. (16).

Fig. 9 shows the comparison of fatigue strength obtained by Eq. (16) for different stress ratios and inclusion sizes with experimental data under axial cycling reported in literature. The parameters $C$ and $l$ are determined by fitting the experimental data with subsurface FGA surrounding the inclusion at $R=-1$ by Shiozawa et al. [33] as shown in Fig. 8b, and $m$ is taken as -0.192 . The value of $\alpha$ is calculated as 0.627 by the fatigue strengths at fatigue life near $4 \times 10^{6}$ cycles for stress ratio $R=-1$ and $R=0$, which has almost the same inclusion size at the fracture origin [36]. Consider that the inclusion size at crack initiation site is between $9 \mu \mathrm{m}$ and $42 \mu \mathrm{m}$ at $R=0$, and is between $9 \mu \mathrm{m}$ and $18 \mu \mathrm{m}$ at $R=0.5$ by Shiozawa et al. [33]. The inclusion size at crack initiation site at $R=0.05$ is between $12 \mu \mathrm{m}$ and $22 \mu \mathrm{m}$ by Nakajima et al. [32]. We take $a_{0, \text { min }}=9 \mu \mathrm{m}$ and $a_{0, \text { max }}=42 \mu \mathrm{m}$ for $R=0, a_{0, \text { min }}=12 \mu \mathrm{m}$ and $a_{0, \text { max }}=22 \mu \mathrm{m}$ for $R=0.05, a_{0, \text { min }}=9 \mu \mathrm{m}$ and $a_{0, \text { max }}=18 \mu \mathrm{m}$ for $R=0.5$. It is seen from Fig. 9 that Eq. (16) correlates well both the effect of stress ratio and inclusion size on fatigue strength for fish-eye mode failure with an FGA surrounding the inclusion at fracture origin, and that the fatigue strength obtained by Eq. (16) using the maximum inclusion size and the minimum inclusion size are the lower and upper bounds of fatigue strength, respectively. Fig. 9 also indicates that, for a couple of specimens with fish-eye mode failure but without an FGA surrounding the inclusion (hollow squares in Fig. 9) at fracture origin, Eq. (16) may not correlate well the effect of inclusion size on fatigue strength. This may be due to that these inclusions (e.g. subsurface inclusion in Fig. 9a) are very close to the surface of specimen, and that it will not take a large number of cycles for the cracks initiated from these inclusions to approach to the surface of specimens. Once the cracks reach the surface of specimen, the air medium will accelerate the growth of the cracks, which results in a shorter fatigue life compared with fatigue life for the inclusion beneath the surface of specimens.

\section{Discussion}

\subsection{Maximum inclusion size estimation}

Meanwhile, it is shown that the fatigue strength obtained by the present model Eq. (14) or Eq. (16) with the maximum inclusion size at fracture origin is regarded as the lower bound of fatigue strength. As known, the inclusion size at fracture origin cannot be determined before fatigue fracture occurs. So, when the model Eq. (14) or Eq. (16) is used to predict the fatigue strength, the maximum inclusion size is an important parameter to be determined first.

The estimation of the maximum inclusion size can be obtained by the statistics of the extreme values (SEV) method and the generalized Pareto distribution (GDP) method [11,32,37]. For the SEV method, it is usually considered that the maximum inclusion size in a certain volume follows Gumbel distribution, i.e.

$F(x)=\exp \left\{-\exp \left[-\left(\frac{x-\lambda}{\beta}\right)\right]\right\}$

where $F(x)$ is the cumulative probability for the largest inclusion no greater than size $x, \lambda$ is location parameter and $\beta$ is scale parameter.

Eq. (17) is rearranged as

$x=\beta\{-\ln [-\ln F(x)]\}+\lambda$

For the estimation of the maximum inclusion in a large volume $V$, a return period $T=V / V_{0}$ is defined, where $V_{0}=S_{0} h$ is the standard inspection volume, $S_{0}$ is the standard inspection area, and $h$ is the average value of measured inclusion size. The maximum inclusion size $x_{V}$ in volume $V$ is considered as the inclusion size that there is only one time to reach $x_{V}$ in the measurement of $T$ times, i.e. $F\left(x_{V}\right)=1-1 / T$. Thus, the maximum inclusion size $x_{V}$ is obtained as $x_{V}=\beta\{-\ln [-\ln (1-1 / T)]\}+\lambda$

For the determination of parameters $\lambda$ and $\beta$, the values of inclusion size $a_{0}$ at fracture origin are ranked from the smallest, and labeled as $a_{0,1} \leqslant a_{0,2} \leqslant \ldots, \leqslant a_{0, n}$. The cumulative probability of the inclusion size no larger than $a_{0, i}$ is calculated by

$F\left(a_{0, i}\right)=i /(n+1)$ 

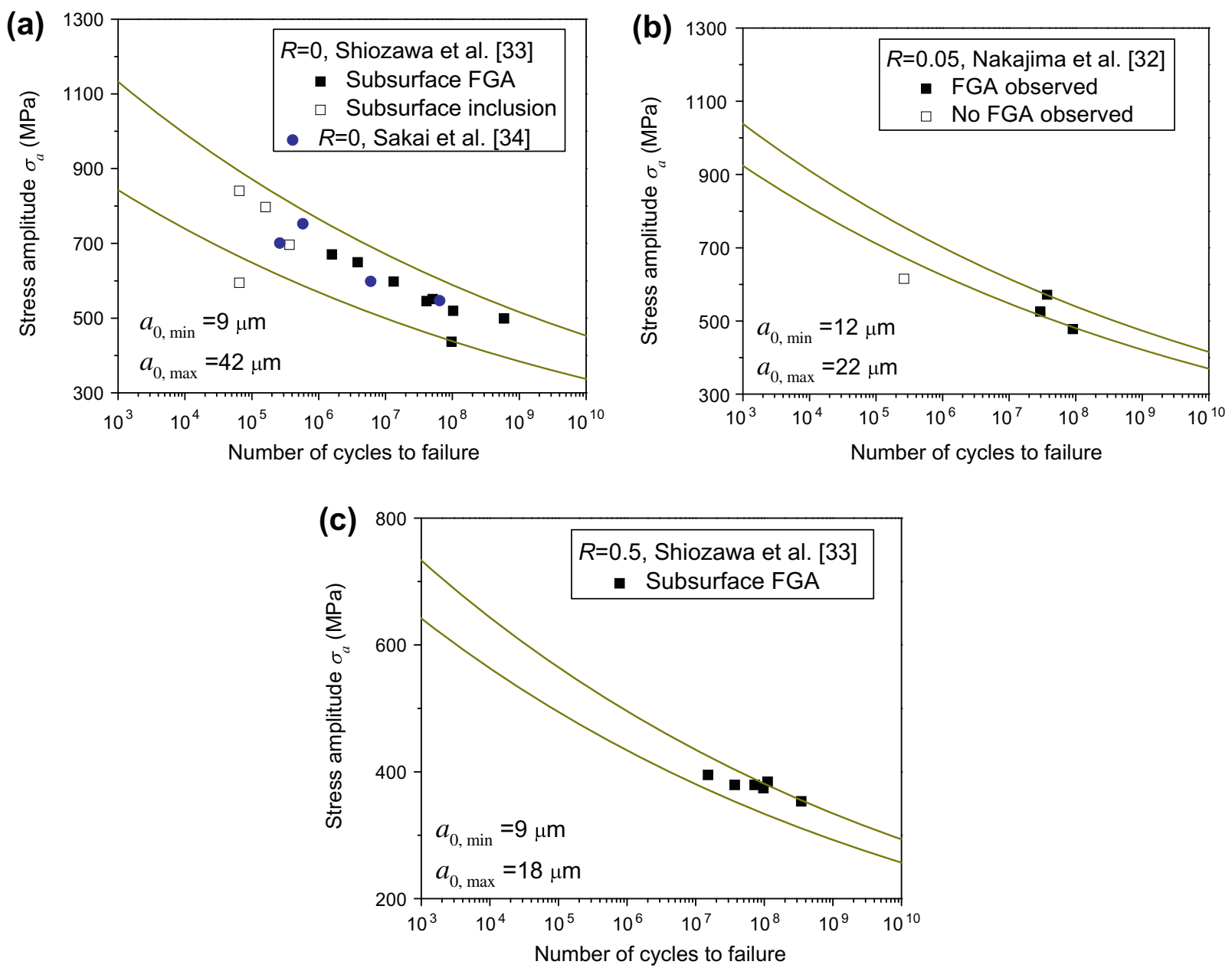

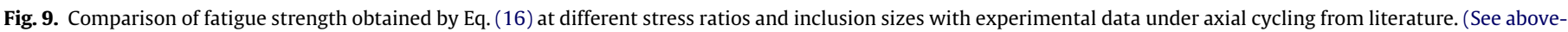
mentioned references for further information.)
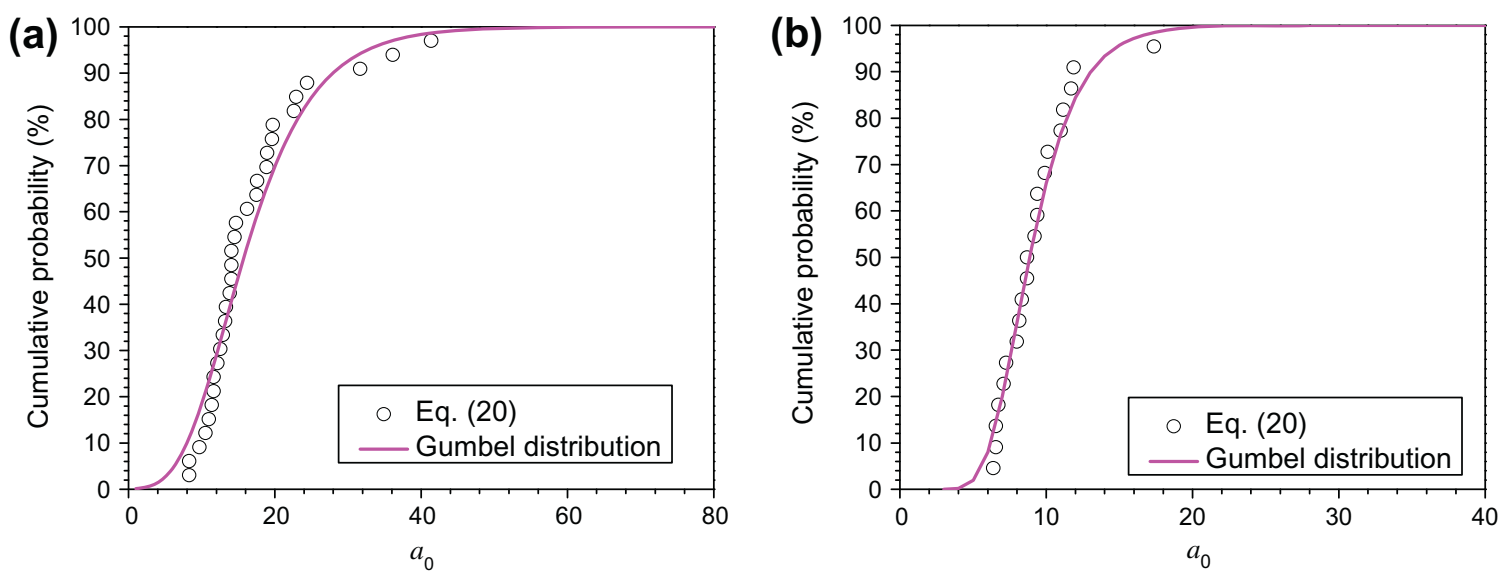

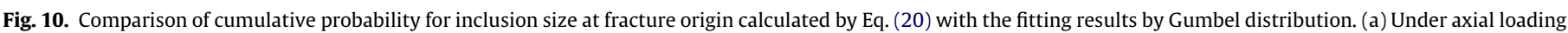
by Shiozawa et al. [33]; and (b) Under rotary bending by Shiozawa et al. [10].

Fig. 10 shows the comparison of the cumulative probability for the inclusion size at fracture origin calculated by Eq. (20) with the fitting results by Gumbel distribution, where $\lambda$ and $\beta$ are obtained by fitting the results using the least square method. It is seen that the inclusion size at fracture origin is well described by Gumbel distribution.

Consider that the inclusion size in steels usually has a log-normal form [37]. So, the log-normal distribution is also attempted to estimate the maximum inclusion size. For the inclusion size, the values of $\ln a_{0}$ are considered and ranked from the smallest, and labeled as $\ln a_{0,1} \leqslant \ln a_{0,2} \leqslant, \ldots, \leqslant \ln a_{0, n}$. The cumulative probability of inclusion size no larger than $a_{0, i}$ is calculated by

$F\left(\ln a_{0, i}\right)=i /(n+1)$

Fig. 11 shows the comparison of the cumulative probability obtained by Eq. (21) with the fitting results by normal distribution, where the population mean and variance are obtained by the 
unbiased estimation. It is observed from Fig. 11 that the inclusion size in natural logarithm at fracture origin is also well described by normal distribution.

For further comparison, Table 2 lists some estimated values of the maximum inclusion size under different probability using Gumbel distribution and log-normal distribution under axial loading and rotary bending, respectively. It is seen that, for both axial loading and rotary bending, the estimated values of the maximum inclusion size using Gumbel distribution are bigger than those using log-normal distribution. This indicates that the estimated value of the maximum inclusion size using Gumbel distribution is more reasonable than the estimated one using log-normal distribution.

\subsection{Fatigue strength prediction}

Fig. 12 shows the comparison of predicted fatigue strength with experimental results using the estimated maximum inclusion size obtained by Gumbel distribution under different probability. The parameters $C$ and $l$ are determined as those in Fig. 8. It is seen that the predicted fatigue strength decreases with the increase of probability $P$ (i.e. the increase of estimated maximum inclusion size).
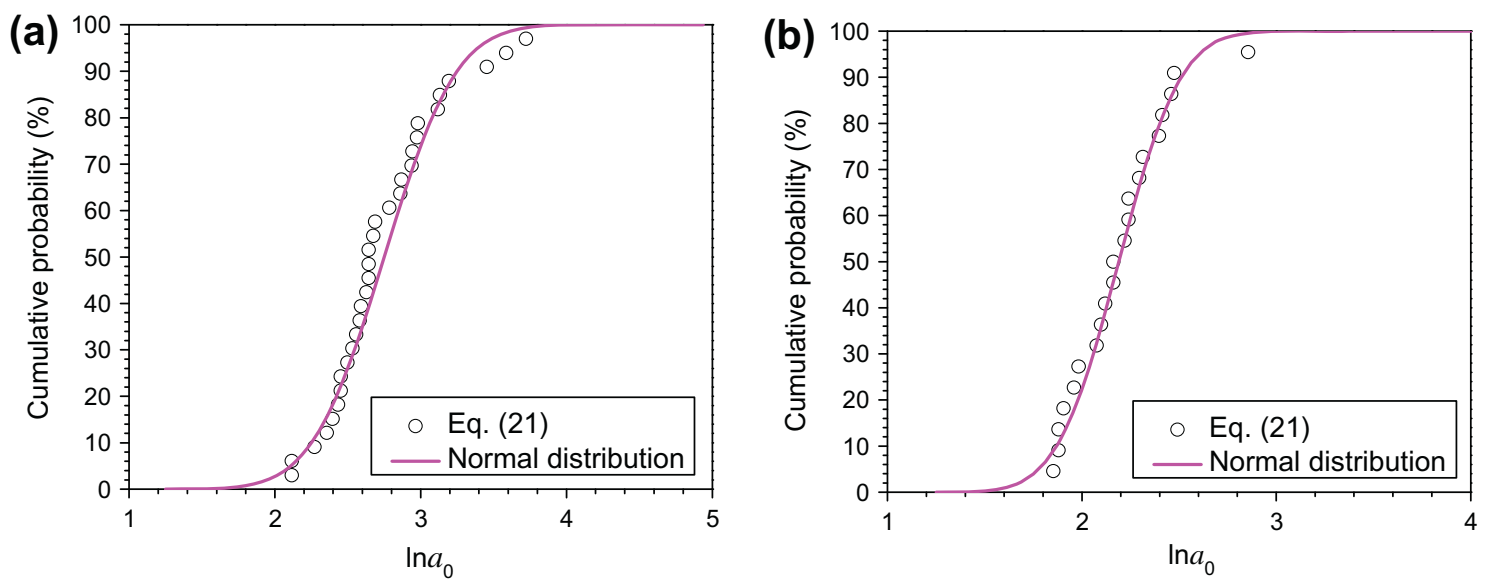

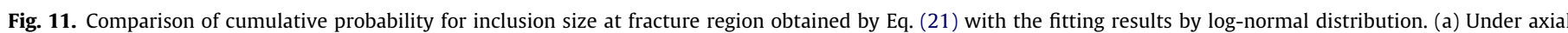
loading by Shiozawa et al. [33]; and (b) Under rotary bending by Shiozawa et al. [10].

Table 2

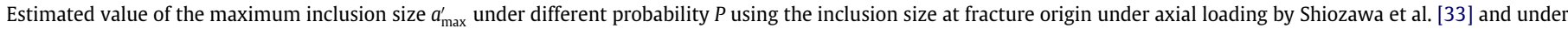
rotary bending by Shiozawa et al. [10], respectively.

\begin{tabular}{|c|c|c|c|c|c|c|c|}
\hline \multicolumn{4}{|c|}{ Axial loading } & \multicolumn{4}{|c|}{ Rotary bending } \\
\hline \multicolumn{2}{|c|}{ Gumbel distribution } & \multicolumn{2}{|c|}{ Log-normal distribution } & \multicolumn{2}{|c|}{ Gumbel distribution } & \multicolumn{2}{|c|}{ Log-normal distribution } \\
\hline$P(\%)$ & $a_{\max }^{\prime}(\mu \mathrm{m})$ & $P(\%)$ & $a_{\max }^{\prime}(\mu \mathrm{m})$ & $P(\%)$ & $a_{\max }^{\prime}(\mu \mathrm{m})$ & $P(\%)$ & $a_{\max }^{\prime}(\mu \mathrm{m})$ \\
\hline 99.9 & 58.13 & 99.9 & 52.2 & 99.9 & 23.39 & 99.9 & 19.36 \\
\hline 99.5 & 47.68 & 99.5 & 42.73 & 99.5 & 19.81 & 99.5 & 17.01 \\
\hline 99 & 43.18 & 99 & 38.74 & 99 & 18.26 & 99 & 15.99 \\
\hline 95 & 32.62 & 95 & 29.73 & 95 & 14.65 & 95 & 13.48 \\
\hline
\end{tabular}
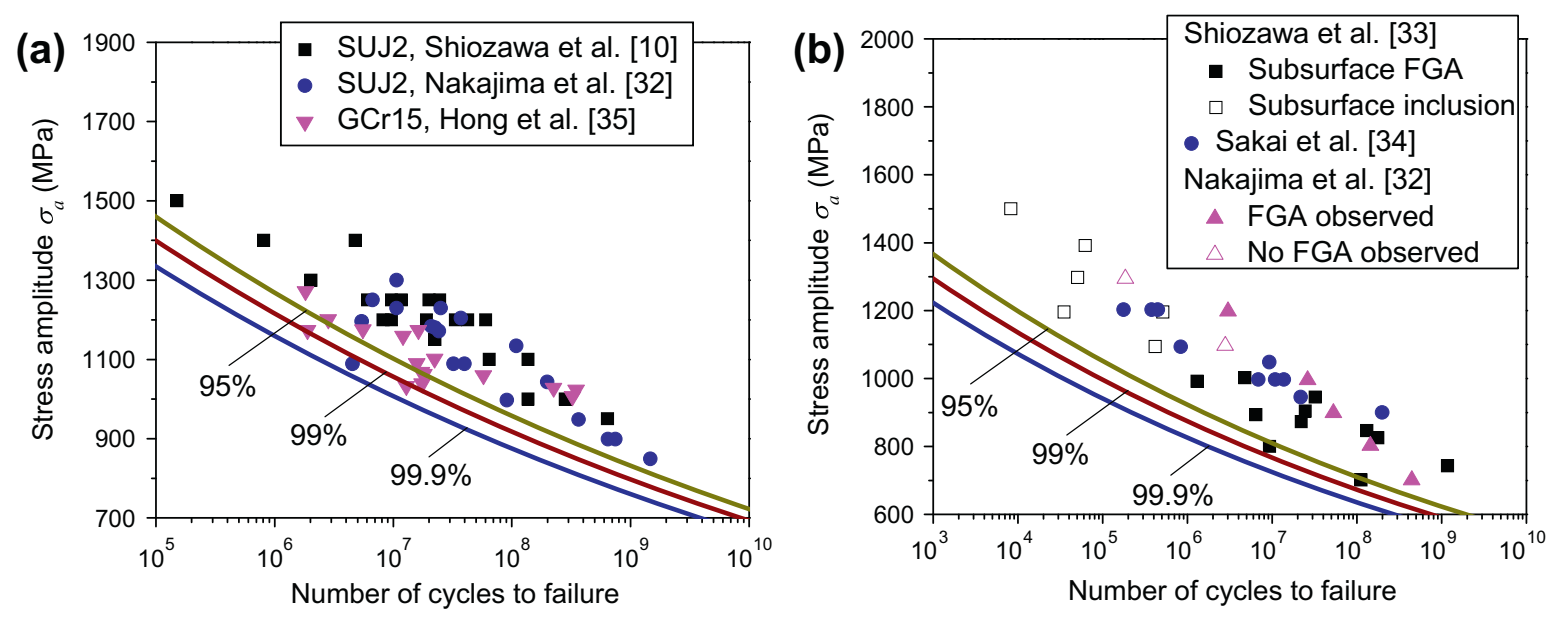

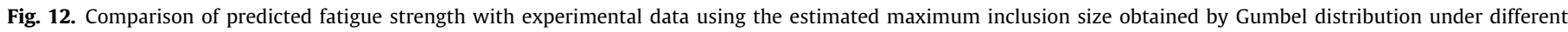
probability. (a) Rotary bending fatigue test, $R=-1$; and (b) Axial loading fatigue test, $R=-1$. 
The predicted fatigue strength is approximately the lower bound for most of the experimental values at $P=99 \%$, and is approximately the lower bound for all of the experimental values at $P=99.9 \%$. This indicates that the fatigue strength obtained by the present model with the estimated maximum inclusion size under a certain probability can be used to predict the fatigue strength of materials. It also indicates that it may be a way to investigate the reliability of fatigue strength through the probability for determining the maximum inclusion size.

\section{Conclusions}

This paper investigates the effect of inclusion size and stress ratio on the fatigue properties of high-strength steels with fish-eye mode failure. The experimental results indicate that the fatigue life reduces by about two orders of magnitude when inclusion size doubles. Then, a model is proposed for predicting the fatigue strength of high-strength steels with fish-eye mode failure, which takes into account the effect of inclusion size and stress ratio. It is shown that the fatigue strength, fatigue life, inclusion size and stress ratio are correlated by the model of $\sigma_{a}=C N_{f}^{l} a_{0}^{m}[(1-R) / 2]^{\alpha}$. The proposed model is verified by the present experimental data and the ones obtained in literature. Then, the model is used to predict the fatigue strength using the estimated maximum inclusion size obtained by Gumbel distribution. The predicted results are in good agreement with the experimental data in literature.

\section{Acknowledgements}

Financial support of the National Natural Science Foundations of China (11172304, 11021262 and 11202210) and the National Basic Research Program of China (2012CB937500) are very much appreciated.

\section{References}

[1] Naito T, Ueda H, Kikuchi M. Fatigue behavior of carburized steel with internal oxides and nonmartensitic microstructure near the surface. Metall Trans A 1984;15:1431-6.

[2] Bathias C, Drouillac L, Le Francois P. How and why the fatigue $S-N$ curve does not approach a horizontal asymptote. Int J Fatigue 2001;23:S143-151.

[3] Dominguez Almaraz GM. Prediction of very high cycle fatigue failure for high strength steels, based on the inclusion geometrical properties. Mech Mater 2008;40:636-40.

[4] Hong Y, Zhao A, Qian G. Essential characteristic and influential factors for veryhigh-cycle fatigue behavior of metallic materials. Acta Metall Sinica 2009;45:769-80.

[5] Qian G, Zhou C, Hong Y. Experimental and theoretical investigation of environmental media on very-high-cycle fatigue behavior for a structural steel. Acta Mater 2011;59:1321-7.

[6] Zhao A, Xie J, Sun C, Lei Z, Hong Y. Effects of strength level and loading frequency on very-high-cycle fatigue behavior for a bearing steel. Int J Fatigue 2012;38:46-56.

[7] Duan Z, Shi H, Ma X. Fish-eye shape prediction with gigacycle fatigue failure Fatigue Fract Eng Mater Struct 2011;34:832-7.

[8] Sakai T, Sato Y, Oguma N. Characteristic $S-N$ properties of high-carbonchromium-bearing steel under axial loading in long-life fatigue. Fatigue Fract Eng Mater Struct 2002;25:765-73.

[9] Murakami Y, Nomoto T, Ueda T. Factors influencing the mechanism of superlong fatigue failure in steels. Fatigue Fract Eng Mater Struct 1999;22:581-90.

[10] Shiozawa K, Lu L, Ishihara S. S-N curve characteristics and subsurface crack initiation behaviour in ultra-long life fatigue of a high carbon-chromium bearing steel. Fatigue Fract Eng Mater Struct 2001;24:781-90.
[11] Li SX. Effects of inclusions on very high cycle fatigue properties of high strength steels. Int Mater Rev 2012;57(2):92-114.

[12] Murakami Y, Nomoto T, Ueda T. On the mechanism of fatigue failure in the superlong life regime $\left(N>10^{7}\right.$ cycles). Part I. influence of hydrogen trapped by inclusions. Fatigue Fract Eng Mater Struct 2000;23(11):893-902.

[13] Zhao A, Xie J, Sun C, Lei Z, Hong Y. Prediction of threshold value for FGA formation. Mater Sci Eng A 2011;528:6872-7.

[14] Shiozawa K, Morii Y, Nishino S, Lu L. Subsurface crack initiation and propagation mechanism in high strength steel in a very high cycle fatigue regime. Int J Fatigue 2006;28:1521-32.

[15] Sakai T. Review and prospects for current studies on very high cycle fatigue of metallic materials for machine structural use. J Solid Mech Mater Eng 2009;3(3):425-39.

[16] Wang QY, Bathias C, Kawagoishi N, Chen Q. Effect of inclusion on subsurface crack initiation and gigacycle fatigue strength. Int J Fatigue 2002:24:1269-74.

[17] Harlow DG, Wei RP, Sakai T, Oguma N. Crack growth based probability modeling of $S-N$ response for high strength steel. Int $\mathrm{J}$ Fatigue 2006;28:1479-85.

[18] Zhao YX, Yang B, Feng MF, Wang H. Probabilistic fatigue $S-N$ curves including the super-long life regime of a railway axle steel. Int J Fatigue 2009;31:1550-8.

[19] Stepanskiy LG. Cumulative model of very high cycle fatigue. Fatigue Fract Eng Mater Struct 2012;35:513-22.

[20] Murakami Y, Endo M. Effects of defects, inclusions and inhomogeneities on fatigue strength. Int J Fatigue 1994;16:163-82.

[21] Wang QY, Berard JY, Dubarre A, Baudry G, Rathery S, Bathias C. Gigacycle fatigue of ferrous alloys. Fatigue Fract Eng Mater Struct 1999;22:667-72.

[22] Akiniwa Y, Miyamoto N, Tsuru H, Tanaka K. Notch effect on fatigue strength reduction of bearing steel in the very high cycle regime. Int $\mathrm{J}$ Fatigue 2006;28:1555-65.

[23] Tanaka K, Akiniwa Y. Fatigue crack propagation behaviour derived from $S-N$ data in very high cycle regime. Fatigue Fract Eng Mater Struct 2002;25:775-84.

[24] Chapetti MD, Tagawa T, Miyata T. Ultra-long cycle fatigue of high-strength carbon steels Part II: estimation of fatigue limit for failure from internal inclusions. Mater Sci Eng A 2003;356:236-44.

[25] Mayer H, Haydn W, Schuller R, Issler S, Furtner B, Bacher-Höchst M. Very high cycle fatigue properties of bainitic high carbon-chromium steel. Int J Fatigue 2009;31:242-9.

[26] Liu YB, Li YD, Li SX, Yang ZG, Chen SM, Hui WJ, et al. Prediction of the $S-N$ curves of high-strength steels in the very high cycle fatigue regime. Int J Fatigue 2010;32:1351-7.

[27] Sun C, Xie J, Zhao A, Lei Z, Hong Y. A cumulative damage model for fatigue life estimation of high-strength steels in high-cycle and very-high-cycle fatigue regimes. Fatigue Fract Eng Mater Struct 2012;35:638-47.

[28] Li W, Sakai T, Li Q, Lu LT, Wang P. Reliability evaluation on very high cycle fatigue property of GCr15 bearing steel. Int J Fatigue 2010;32:1096-107.

[29] Slámečka K, Pokluda J, Kianicová M, Major Š, Dvořák I. Quantitative fractography of fish-eye crack formation under bending-torsion fatigue. Int J Fatigue 2010;32:921-8.

[30] Yang ZG, Li SX, Liu YB, Li YD, Li GY, Hui WJ, et al. Estimation of the size of GBF area on fracture surface for high strength steels in very high cycle fatigue regime. Int J Fatigue 2008;30:1016-23.

[31] Li YD, Yang ZG, Li SX, Liu YB, Chen SM. Correlations between very high cycle fatigue properties and inclusions of $\mathrm{GCr} 15$ bearing Steel. Acta Metall Sin 2008;44:968-72.

[32] Nakajima M, Tokaji K, Itoga H, Shimizu T. Effect of loading condition on very high cycle fatigue behavior in a high strength steel. Int J Fatigue 2010;32:475-80.

[33] Shiozawa K, Hasegawa T, Kashiwagi Y, Lu L. Very high cycle fatigue properties of bearing steel under axial loading condition. Int J Fatigue 2009;31:880-8.

[34] Sakai T, Sato Y, Nagano Y, Takeda M, Oguma N. Effect of stress ratio on long life fatigue behavior of high carbon chromium bearing steel under axial loading. Int J Fatigue 2006;28:1547-54

[35] Hong YS, Zhao AG, Qian GA, Zhou CE. Fatigue strength and crack initiation mechanism of very-high-cycle fatigue for low alloy steels. Metall Mater Trans A 2012;43(8):2753-62

[36] Sun C, Hong Y. Correlation of crack growth rate and stress ratio for fatigue damage containing very high cycle fatigue regime. Theor Appl Mech Lett 2012;2:031004.

[37] Atkinson HV, Shi G. Characterization of inclusions in clean steels: a review including the statistics of extremes methods. Prog Mater Sci 2003;48:457-520. 